\title{
Gold layers characterization by Ion Beam Analytical Techniques: from Semiconductors to cultural heritage artefacts
}

\author{
Corregidor, V. ${ }^{*}$, Alves, L.C. ${ }^{* * * * * *}$
}

* IPFN, Campus Tecnológico e Nuclear, Instituto Superior Técnico, Universidade de Lisboa, E.N. 10, 2686953 Sacavém, Portugal

** CFNUL, Centro de Física Nuclear da Universidade de Lisboa, Av. Prof. Gama Pinto, 2, 1649-003 Lisboa, Portugal

**** C2TN, Campus Tecnológico e Nuclear, Instituto Superior Técnico, Universidade de Lisboa, E.N. 10, 2686-953 Sacavém, Portugal

email : vicky.corregidor@ ctn.ist.utl.pt

Ion Beam Analytical (IBA) techniques, individually or in combined use, are able to determine not only the elemental composition of a sample with high accuracy and sensitivity, but also the distribution of the elements over the surface and in some cases their depth profile through the first microns from the surface.

There are a wide variety of analytical problems and materials with many different applications that can be studied by these techniques. Some examples are: semiconductor alloys, metallic contacts, heterostructures, thin films, biological samples or cultural heritage artefacts. The reasons of this wide field of applications are their versatility, their simple or non-existent sample preparation requirements and their non-destructive character. Regarding large samples where sampling is not allowed (as in the cases of archaeological artefacts) or fragile samples which cannot stand vacuum conditions, an external beam setup can be used.

In this work results obtained on selected examples of gold deposition layers will be presented. In the first case, gold has been used as a metal of choice to obtain ohmic contacts on CdZnTe (CZT) substrates due to its electrical good performance properties in order to obtain fine room temperature nuclear detector response. In a second example, gold has been used to obtain golden surfaces on specific parts of a silver artefact from the XVI century, which were applied following the leaf method. In both cases, gold layer thicknesses and diffusion profiles were obtained whether using Rutherford Backscattering Spectrometry (RBS) by means of a $2 \mathrm{MeV}$ alpha particle beam or by combining Proton Induced X-ray Emission (PIXE) and RBS data using the external proton beam set-up [1] respectively.

Figure 1 shows the RBS spectra obtained from different Au contacts deposited on CZT substrates using different coating methods. According with the figure, there is always an inter-diffusion layer between the contact and the substrate and also the development of a $\mathrm{TeO}_{2}$ layer. The evaporation method presents the lower inter-diffusion layer, while the electroless method presents the strongest intermixing layer of $\mathrm{Au}, \mathrm{TeO}_{2}$ and CZT. On the other hand, the sputtering method produces a very rich $\mathrm{TeO}_{2}$ layer between the Au layer and the bulk CZT. This could explain the quasi-ohmic behaviour displayed by the contacts created by electroless and evaporation methods, which also give a better detector performance than sputtering [2].

Figure 2 shows the 2D maps - $\mathrm{Au}$ and $\mathrm{Cu}$ - recorded in a golden region of the silver artefact. Usually, copper is added to silver to give it strength while preserving the ductility and beauty of this precious metal. Using the external proton beam and combining RBS with PIXE (fig. 3), it was possible to obtain the thickness and composition of the gold layer (table 1). Considering the low diffusion profile of the gold, it can be deduced that it was produced using the leaf method. In fact, taking into consideration the gold concentration and its diffusion profile it is possible to distinguish between different manufacturing methods to produce golden surfaces, i.e. the use of gold leaf or fire gilding method [3]. 
V. Corregidor acknowledges the funding support from the FCT-Ciência program. The work was partially supported by FCT-Portugal (PEST-OE/FIS/UI0275/2011).

[1] Corregidor, V., et al., e-conservation magazine, 22, 40-52, 2011.

[2] Zheng, Q. et al., J. Phys. D: Appl. Phys., 45, 175102, 2012.

[3] Corregidor, V., et al., Nucl. Instrum. Methods B, 269, 3049-3053, 2011.

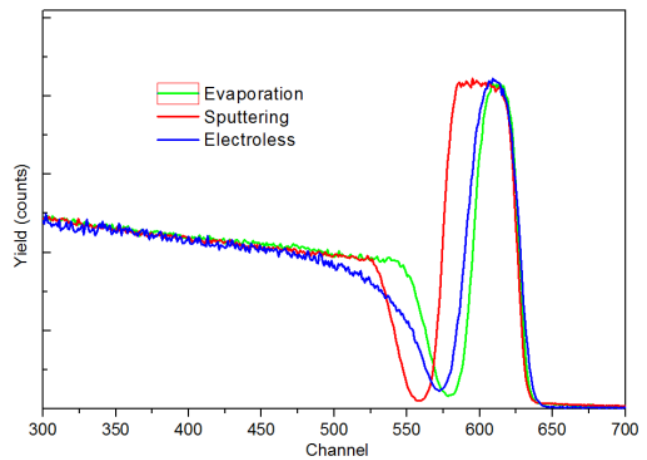

Figure 1 - RBS spectra obtained from different Au contacts deposited on CdZnTe substrates using different coating methods.

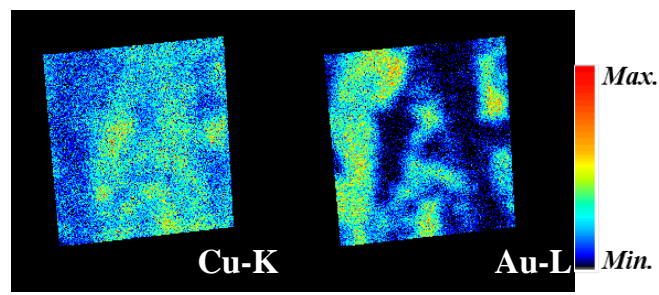

Fig. 2 - 2D maps of $\mathrm{Au}$ and $\mathrm{Cu}(800 \times 800 \mu \mathrm{m} 2)$ recorded in a golden region of a silver artefact.

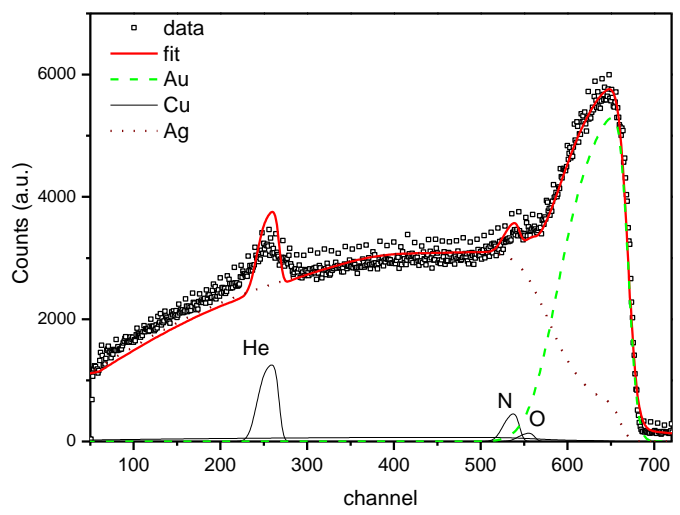

Fig. 3 - RBS spectrum and fit obtained with the external proton beam. Point analysis on a golden surface prepared by the gold leaf method.

\begin{tabular}{|c|c|c|c|}
\hline $\begin{array}{c}\text { Thick. } \\
\text { wt(\%) }\end{array}$ & $\mathrm{Cu}$ & $\mathrm{Ag}$ & $\mathrm{Au}$ \\
\hline$\sim 466 \mathrm{~nm}$ & 1.4 & 24.3 & 74.3 \\
\hline$\sim 356 \mathrm{~nm}$ & 2.0 & 35.5 & 62.5 \\
\hline$\sim 270 \mathrm{~nm}$ & 2.5 & 43.9 & 53.6 \\
\hline substrate & 5.4 & 94.6 & - \\
\hline
\end{tabular}

Table 1. Gold depth profile on the silver artefact. 